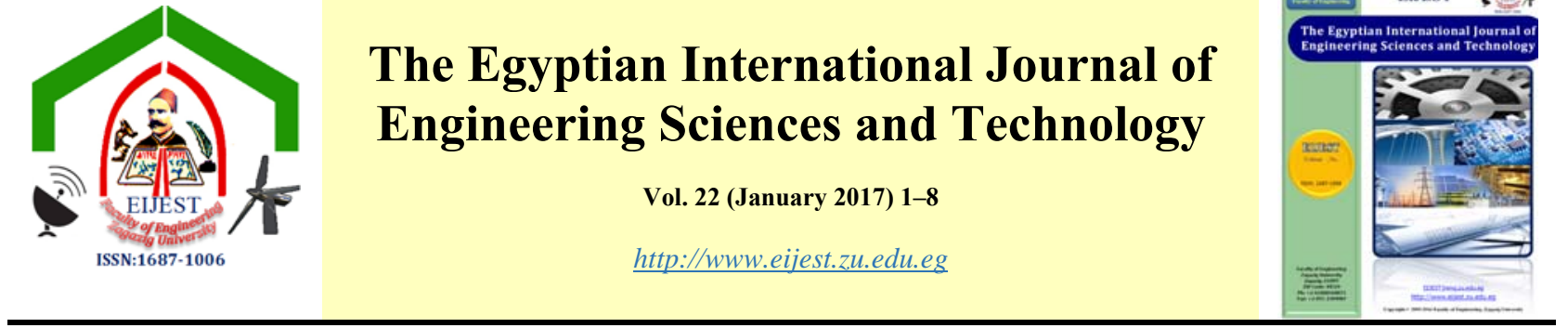

\title{
Examining Free Jump Parameters under the Effect of Two Vertical Overlapping Gates (TVOG)
}

\author{
Gamal M. Abdel-Aal ${ }^{\text {a }}$, Osama K. Saleh ${ }^{\mathrm{a}}$, Mohamed A. Nassar ${ }^{\mathrm{b}}$, Abeer A. Abdel-Ghany ${ }^{\mathrm{c} *}$ \\ ${ }^{a}$ Water Engineering and Water Structures Department, Faculty of Engineering, Zagazig University, Egypt, \\ ${ }^{\mathrm{b}}$ Department of Construction Engineering, College of Engineering in Al-Qunfudhah, Umm Al-Qura University, KSA, On leave from Water \\ Engineering and Water Structures Department, Faculty of Engineering, Zagazig University, Egypt, \\ ${ }^{\mathrm{c}}$ Graduate student, Faculty of Engineering, Zagazig University, Egypt. \\ A B S T R A C T
}

\begin{tabular}{l}
\hline A R T I C L E I N F O \\
\hline Article history: \\
Received: 2 May 2016 \\
Received in revised form: \\
5 July, 24 July and 30 \\
August 2016 \\
Accepted: 31 August 2016 \\
Available online: \\
1 September 2016 \\
\hline Keywords: \\
Hydraulic Jump \\
Vertical Gates \\
Apron \\
Overlapping gates \\
Lost energy
\end{tabular}

The Jump downstream vertical gate is an effective tool to waste the flow energy. The current experimental work deliberates for the parameters of jump downstream Two Vertical Overlapping Gates (TVOG). The proposed TVOG allows dividing the flow via two openings. The lower one is under the lower gate, while the upper one is proposed between the gates. Experiments are examined on a rectangular flume of $66 \mathrm{~cm}$ width, $65.5 \mathrm{~cm}$ depth and $16.2 \mathrm{~m}$ length. The ideal percentage of the upper opening related to the lower one is detected experimentally. It is found that, working TVOG by upper opening fifty percent of the lower one wastes the flow energy by $52 \%$ and shrinks the basin length by $4.3 \%$.

Lost energy

() 2017 EIJEST. All rights reserved

$\begin{array}{ll}\begin{array}{c}\text { Nomenclature } \\ \left(\mathrm{E}_{\mathrm{UP}}-\mathrm{E}_{2}\right) / \mathrm{E}_{2}\end{array} & \text { The percentage of lost energy } \\ \mathrm{G}_{1} & \text { The lower gate opening, } \\ \mathrm{G}_{2} & \text { The upper gate opening, } \\ \mathrm{H}_{1} & \text { The measured depth between gates } \\ \mathrm{H}_{2} & \text { The depth on the upper gate } \\ \mathrm{L}_{\mathrm{J}} / \mathrm{y}_{2} & \text { The percentage of length of } \mathrm{H} \text {. jump } \\ \mathrm{Q}_{\mathrm{ml}} & \text { The lower discharge } \\ \mathrm{Q}_{\mathrm{T}} & \text { The total discharge } \\ \mathrm{y}_{2} / \mathrm{H}_{\mathrm{UP}} & \text { The end jump depth percentage } \\ \mathrm{y}_{2} / \mathrm{y}_{1} & \text { The ratio of the jump depths } \\ \mathrm{F}_{2} & \text { The sequent Froude value } \\ \mathrm{W} & \text { Constant width } \mathrm{W}=7.5 \mathrm{~cm}\end{array}$

\section{Overview}

The adjustments of the basins downstream gates are a need to reduce the high cost of constructions and to increase the structure's safety. The simplest way to adjust the basin is increasing the energy lost through $\mathrm{H}$. jumps and shortening the basin. The main categories of the adjustments contain the following: accessories into the basin, adapting of the geometrical basin shape and enhancing of gates. The three categories are reviewed below.

The first category includes many papers discussed the issue of locating accessories into apron. Negm, et al. (2003) identified that the negative " $B$ " jump is longer than the negative "A" jump for the similar flow circumstances. In addition, locating the step at fifty percent of the basin gave the smallest length of $\mathrm{H}$. jumps downstream gates.

Negm, et al. (2002b) researched the submerged H. jump in a basin, including an end sill and negative step. Theoretical and statistical equations are proposed to estimate the jump properties.

Habib and Nassar (2014) proposed a movable sill in a basin to reduce the lengths and depths of jumps. The proposed sill increased the energy lost by $35 \%$. Habib and Nassar (2013) examined properties of jumps at a presence of roughness. It was indicated that, coverings of the basin by $90 \%$ of the proposed

\footnotetext{
* Corresponding author: Tel. +2-01060083117

E-mail address: civileng_2222@hotmail.com.
} 
elements lift the ratio of lost energy to $17 \%$. Alikhani, et al. (2010) supposed that the vertical sill is significantly affecting the jump parameters.

The second category includes researchers studied adjusting of the geometry of the basin. Saleh, et al. (2003) studied locating asymmetric sill on the scour downstream of sudden expansion basin. The proposed sill expressively decreased the scour depth. Matin, et al. (1998) presented a model to predict the ratio of the jump depths in abrupt enlargement case.

The third category includes the improving of the gates or the use of multiple openings. Abdel-Aal et al. (2014a) explored the mixture between Fayoum weir and adjusted gates up the weir's crest. AbdelAal et al., (2014b) proposed a gate with an inclined hose of $330^{\circ}$ to decrease the jump depth ratio by $12.3 \%$.

Abdel-Aal et al., (2004) explored the jump parameters downstream multi-gates in lateral direction. The optimum operation of the gates was defined to reduce the extent of jump and to increase energy loss.

Negm, et al. (2007) studied the effects of submerged jump downstream multi-gates on scour patterns. It was referred that, the scour depth depended the near bed velocity and the operated gates. Negm, et al. (2002a) and Dehghani, et al. (2010) widely studied the effects of the mixture between gates and weir.

The current experimental work studied the geometry prosperities of jump downstream of Two Vertical Overlapping Gates (TVOG). TVOG allows passing the flow under the lower gate and between proposed two gates. The previous revision proved that, using two vertical overlapping gates were not investigated.

\section{The Description of Tests}

The tests were applied in a fixed bed flume of the lateral breadth $=66 \mathrm{~cm}$, the section depth $=65.5 \mathrm{~cm}$ and the total length of working part $=16.2 \mathrm{~m}$. The water source exists in a sump tank and is used by a suitable pump.

The model consists of two simple overlapping vertical gates move through $2 \mathrm{~cm}$ side slots in wing walls. The walls were made from a woody material with a protective layer of paint; see the model particulars as showing in Fig. (1).

Figure (2) presents an image for tested models. The used apparatus for measuring of discharge $\left(\mathrm{Q}_{\mathrm{T}}\right)$ is a calibrated sharp edge rectangular weir. The used weir is galvanized steel plate prepared to the measuring conditions. The apparatus was calibrated by an ultrasonic flow meter.

The measures of the investigated phenomenon are applied in the hydraulics laboratory in Water engineering and water structures Dept., Faculty of Eng., Zagazig Univ., Egypt.

The tests include two groups of measures:

- The first group contains the measures of jump parameters in the situation of operating the lower gate only. It is titled as the lower gate situation, and

- The second group includes the operating of the upper gate with opening height of a definite percentage of the lower gate. The different investigated percentages are $\mathrm{G}_{2} / \mathrm{G}_{1}=50 \%, 75 \%$, $100 \%$ and $150 \%$.

\section{A Comparison with the Previous Studies.}

As mentioned before, the proposed apparatus consists of two gates, see figure (1). Measuring the amount of discharge of each opening is an important during the analysis. As well as, the calibration of experimental measures is very urgent.

The measured data of the ratios of the jump depths for the lower gate needs to be compared with some equations of similar cases. Hager (1985) presented an statement for ratios of the jump depths for abrupt enlargement case as assumed in Eq. (1). Herbrand (1973) as notified by Kordi and Abustan (2011) presented another formula for ratios of the jump depths for abrupt enlargement case as assumed in Eq. (2).The Blanger equation describes the ratio of the jump depths for classical jump can be written as Eq. (3). Another form for the classical jump case can be rewritten as equation (4).

$$
\begin{aligned}
& \left(\mathrm{y}_{2} / \mathrm{y}_{1}\right)=\left(1 / \alpha^{1 / 2}\right)\left[\left(2^{0.5} \mathrm{~F}_{1}\right)-0.5\right] \\
& \mathrm{y}_{2}=(1 / \alpha)^{3 / 8}\left(\mathrm{y}_{2}\right)_{\text {classic }} \\
& \left(\mathrm{y}_{2} / \mathrm{y}_{1}\right)_{\text {classic }}=0.5\left[\left(8 \mathrm{~F}_{1}^{2}+1\right)^{0.5}-1\right] \\
& \left(\mathrm{y}_{1} / \mathrm{y}_{2}\right)_{\text {classic }}=0.5\left[\left(8 \mathrm{~F}_{2}{ }^{2}+1\right)^{0.5}-1\right]
\end{aligned}
$$



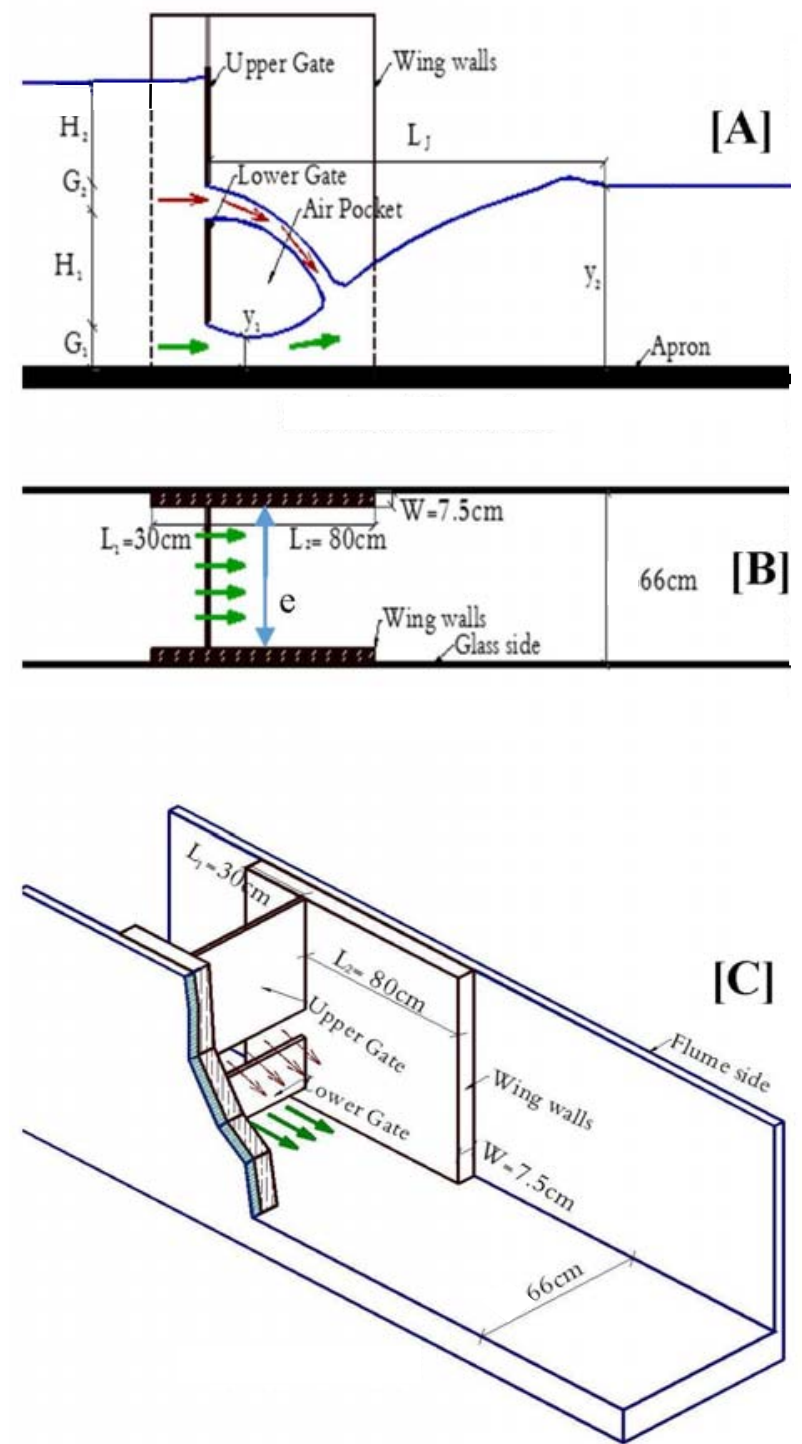

Fig. 1: Definition drafts of the fixed bed flume including

the proposed gates $[\mathrm{A}]$ an elevation $[\mathrm{B}]$ a horizontal plan $[\mathrm{C}]$ an isometric

The present experimental data for the case of the lower gate situation with expansion value of $\alpha=B / e$ $=1.26$ was compared with the Blanger Equation (3) \& Hager (1985) for abrupt enlargement and Herbrand (1973). The measures of the ratio of the jump depths $\mathrm{y}_{2} / \mathrm{y}_{1}$ are figured against initial Froude value $F_{1}$, see figure (3). The figure proves the high accuracy of the recent measures. In fact, the differences are due to the effectiveness of the place of the enlargement's start. The line of Blanger Equation (3) shows the effectiveness of the enlargement on the jump phenomena as it reduces the values of $y_{2} / y_{1}$.

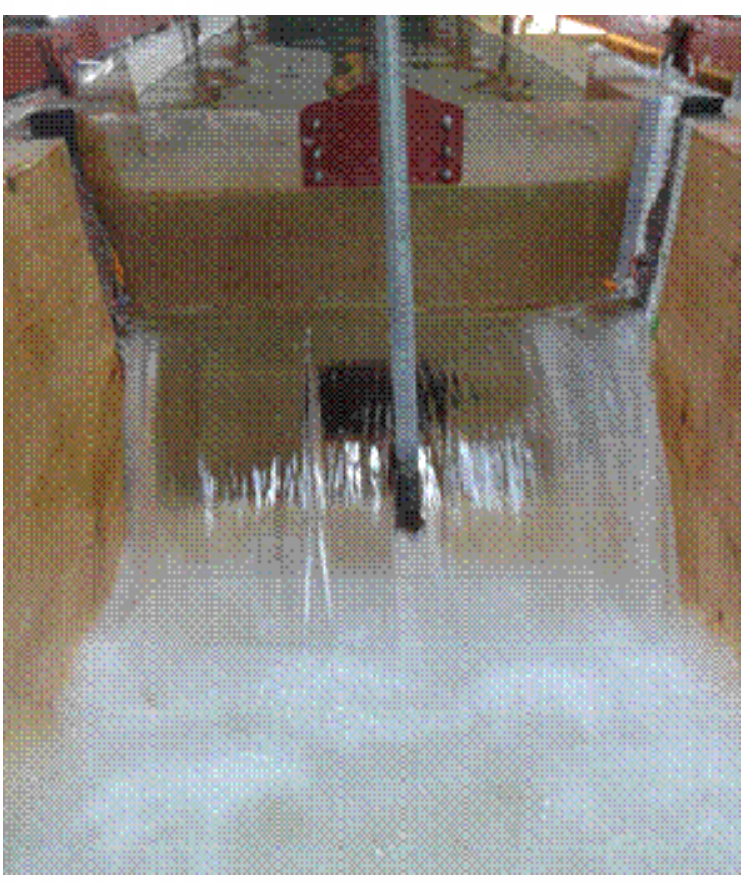

Fig. 2: An image of the tested model

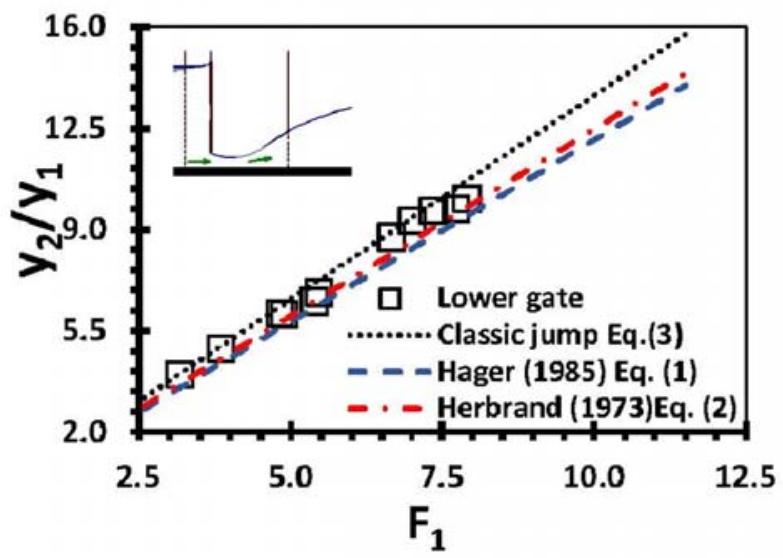

Fig. 3: The relationships between $\mathrm{y}_{2} / \mathrm{y}_{1}$ against $F_{1}$ for the recent measurements and the available equations.

\section{Jump Parameters for Only the Lower Gate Situation $\left(\mathbf{G}_{2} / \mathbf{G}_{1}=\mathbf{0}\right)$}

The jump parameters for the lower gate situation are figured against the sequent Froude value $F_{2}$ as existing in figure (4). The parameters are inclusive of the percentage of the end depth of jump to flow upstream gates $\mathrm{y}_{2} / \mathrm{H}_{\mathrm{UP}}$, the percentage of length of $\mathrm{H}$. jump to the end depth $\mathrm{L}_{\mathrm{J}} / \mathrm{y}_{2}$, and the percentage of lost energy via the apparatus to the sequent energy $\left(\mathrm{E}_{\mathrm{UP}}-\mathrm{E}_{2}\right) / \mathrm{E}_{2}$. 


\section{Jump Parameters For Two Vertical Overlapping Gates (TVOG)}

The jump parameters for different investigated situations of the Two Vertical Overlapping Gates (TVOG) are figured against the sequent Froude value $F_{2}$ as existing in figures (5,6 and 7). Figure (5) presents the percentage of the end depth of jump to flow upstream gates $\mathrm{y}_{2} / \mathrm{H}_{\mathrm{UP}}$ for $\mathrm{G}_{2} / \mathrm{G}_{1}=50 \%, 75 \%$, $100 \%$ and $150 \%$ against $F_{2}$. It is apparent that, the $\mathrm{y}_{2} / \mathrm{H}_{\mathrm{UP}}$ magnifies by the developing of the sequent Froude value $F_{2}$ for all studied amounts of $\mathrm{G}_{2} / \mathrm{G}_{1}$. Figure (6) presents the percentage of length of $\mathrm{H}$. jump to the end depth of jump $\mathrm{L}_{\mathrm{J}} / \mathrm{y}_{2}$ for $\mathrm{G}_{2} / \mathrm{G}_{1}$ $=50 \%, 75 \%, 100 \%$ and $150 \%$ against $F_{2}$.
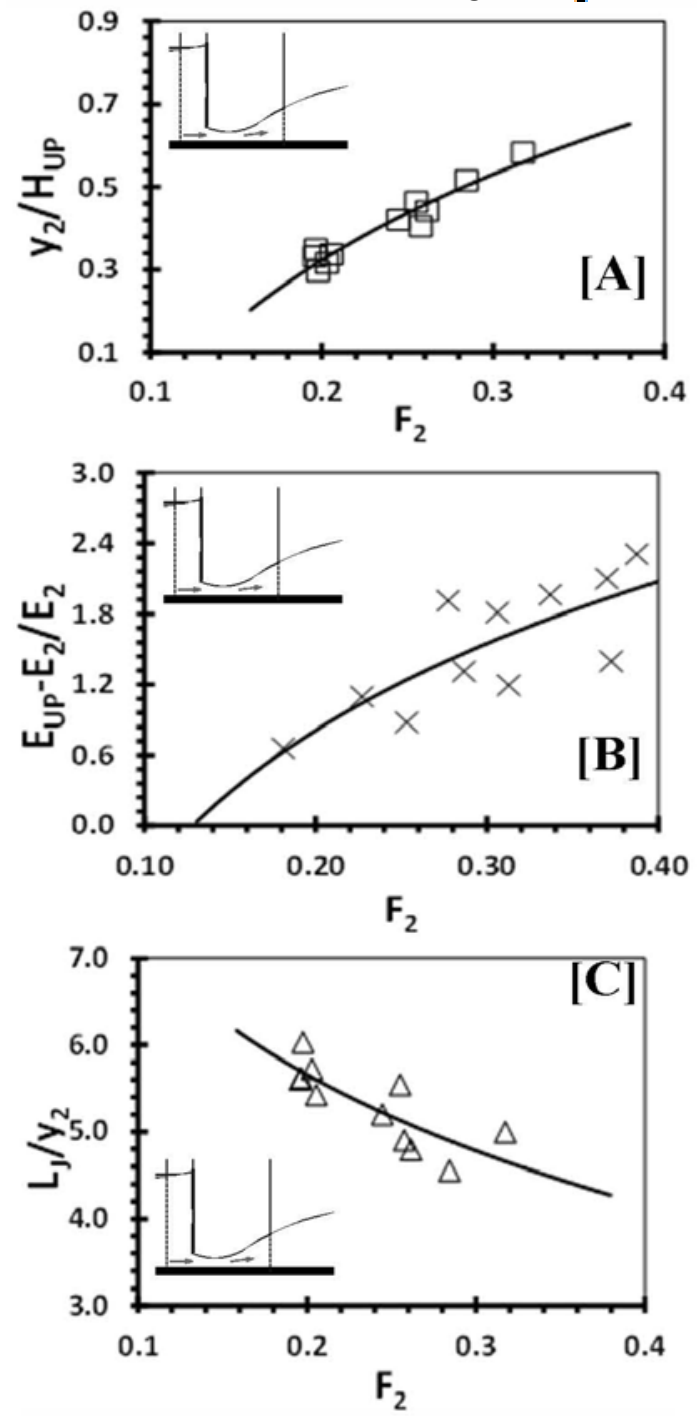

Fig. 4: The jump parameters against $F_{2}$ for the lower gate situation $[\mathrm{A}] \mathrm{y}_{2} / \mathrm{H}_{\mathrm{UP}} \quad[\mathrm{B}]\left(\mathrm{E}_{\mathrm{UP}}-\mathrm{E}_{2}\right) / \mathrm{E}_{2}$ [C] $\mathrm{L}_{\mathrm{J}} / \mathrm{y}_{2}$
It is apparent that, $\mathrm{L}_{\mathrm{J}} / \mathrm{y}_{2}$ decreases by the developing of the sequent Froude value $F_{2}$ for all studied amounts of $\mathrm{G}_{2} / \mathrm{G}_{1}$.

Figure (7) presents the percentage of lost energy via the apparatus to the sequent energy $\left(\mathrm{E}_{\mathrm{UP}}-\mathrm{E}_{2}\right) / \mathrm{E}_{2}$ for $\mathrm{G}_{2} / \mathrm{G}_{1}=50 \%, 75 \%, 100 \%$ and $150 \%$ against $F_{2}$. It is apparent that, $\left(E_{U P}-E_{2}\right) / E_{2}$ decreases by the developing of the sequent Froude value $\bar{F}_{2}$ for all studied percentages of $\mathrm{G}_{2} / \mathrm{G}_{1}$.
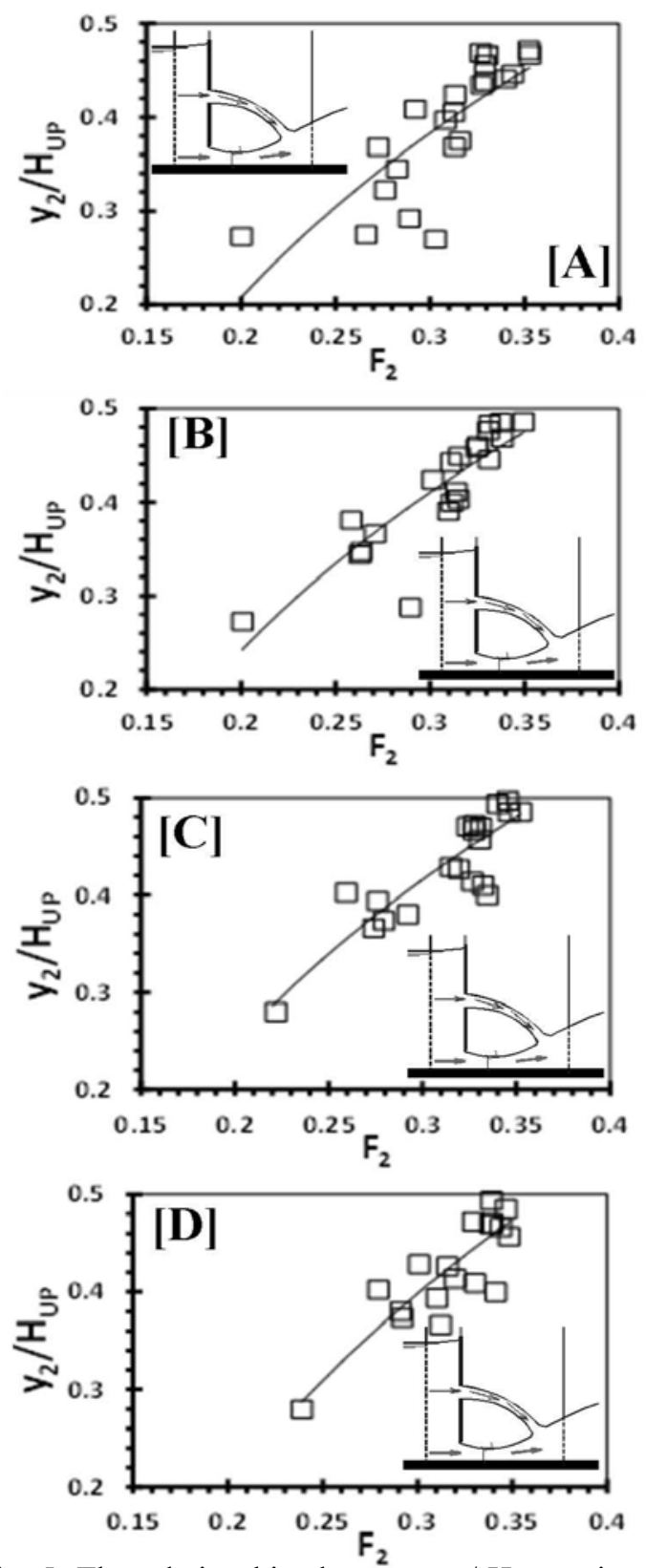

Fig. 5: The relationships between $\mathrm{y}_{2} / \mathrm{H}_{\mathrm{UP}}$ against $\boldsymbol{F}_{2}$ [A] $\mathrm{G}_{2} / \mathrm{G}_{1}=50 \%$ [B] $\mathrm{G}_{2} / \mathrm{G}_{1}=75 \%$ [C] $\mathrm{G}_{2} / \mathrm{G}_{1}=100 \%$ [D] $\mathrm{G}_{2} / \mathrm{G}_{1}=150 \%$ 
EIJEST Vol. 22 (January 2017) 1-8
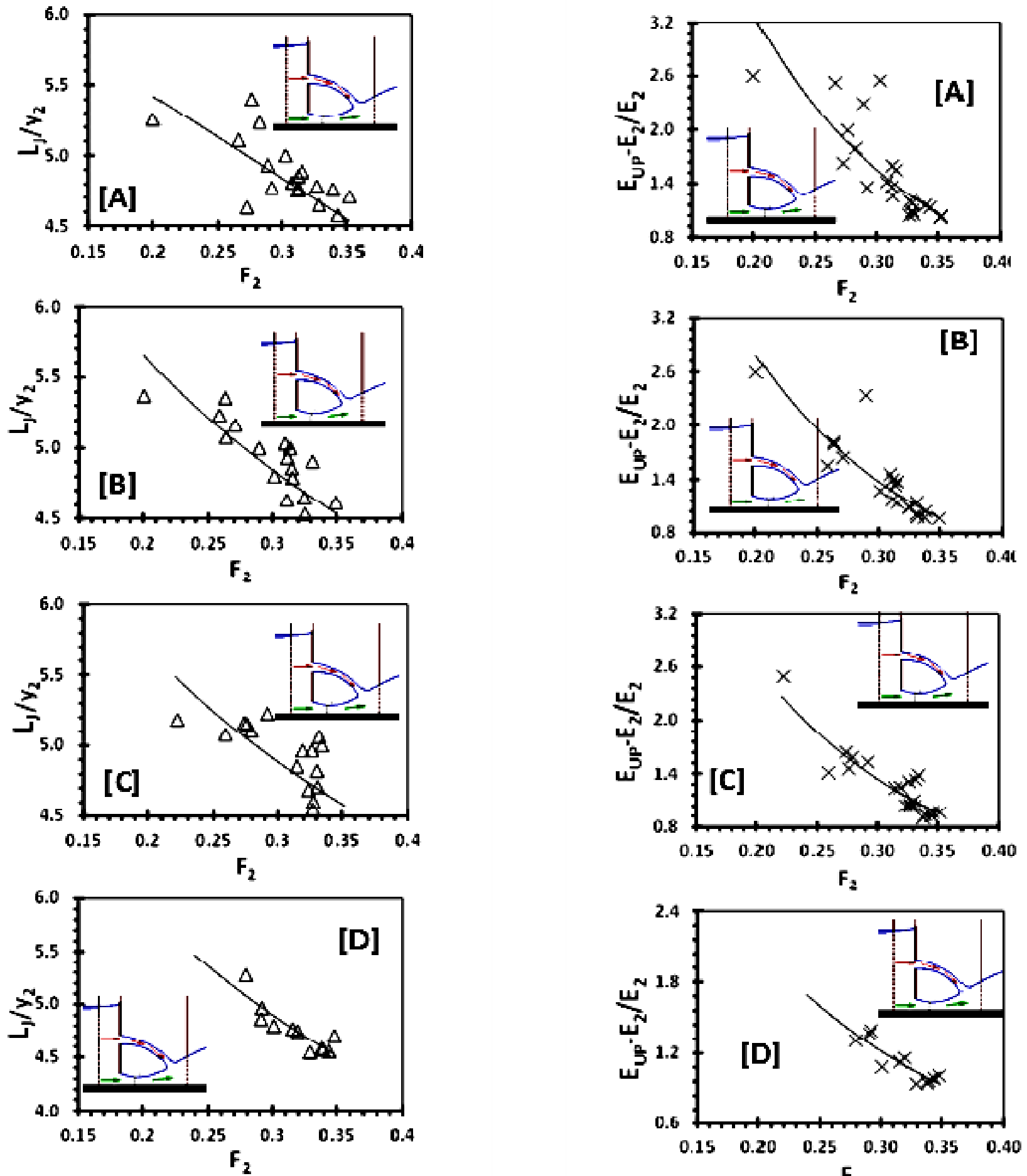

Fig. 6: The rel ationships between $L_{J} / y_{L}$ against $F_{2}[\mathrm{~A}] \mathrm{G} 2 / \mathrm{G}_{1}=50 \%[\mathrm{~B}] \mathrm{G}_{2} / \mathrm{G}_{1}=75 \%$ [C] $\mathrm{G}_{2} / \mathrm{G}_{1}=100 \%[\mathrm{D}] \mathrm{G}_{2} / \mathrm{G}_{1}=150 \%$

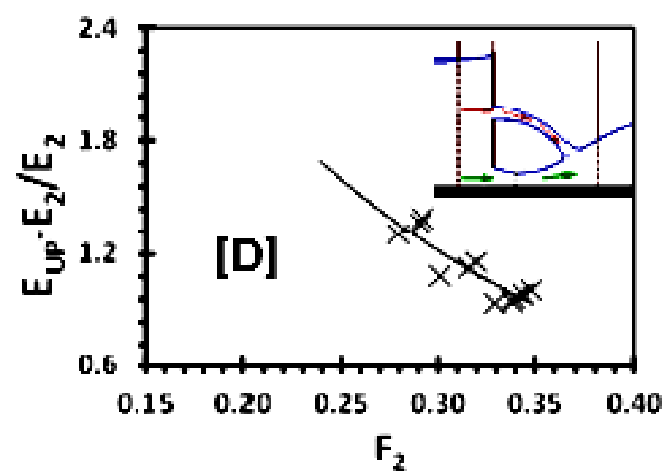

Fig. 7: The relationships between $\frac{E_{U P}-E_{2}}{E_{2}}$ against $F_{2}[\mathrm{~A}] \mathrm{G}_{2} / \mathrm{G}_{1}=50 \%[\mathrm{~B}] \mathrm{G}_{2} / \mathrm{G}_{1}=75 \%[\mathrm{C}] \mathrm{G}_{2} / \mathrm{G}_{1}$ $=100 \%[\mathrm{D}] \mathrm{G}_{2} / \mathrm{G}_{1}=150 \%$ 
Figure (8) presents relationships between jump parameters for different investigated situations of the Two Vertical Overlapping Gates (TVOG) against $F_{2}$. It can be gotten that, the situation of $\mathrm{G}_{2} / \mathrm{G}_{1}=50 \%$ gives the lower percentage of the end depth of jump to flow upstream gates $\mathrm{y}_{2} / \mathrm{H}_{\mathrm{UP}}$, as existing in figure (8A).

In the opposite way, the situation of (TVOG) of $\mathrm{G}_{2} / \mathrm{G}_{1}=50 \%$ gives the major percentage of lost energy via the apparatus to the sequent energy $\left(\mathrm{E}_{\mathrm{UP}}-\mathrm{E}_{2}\right) / \mathrm{E}_{2}$, see figure $(8 \mathrm{~B})$.
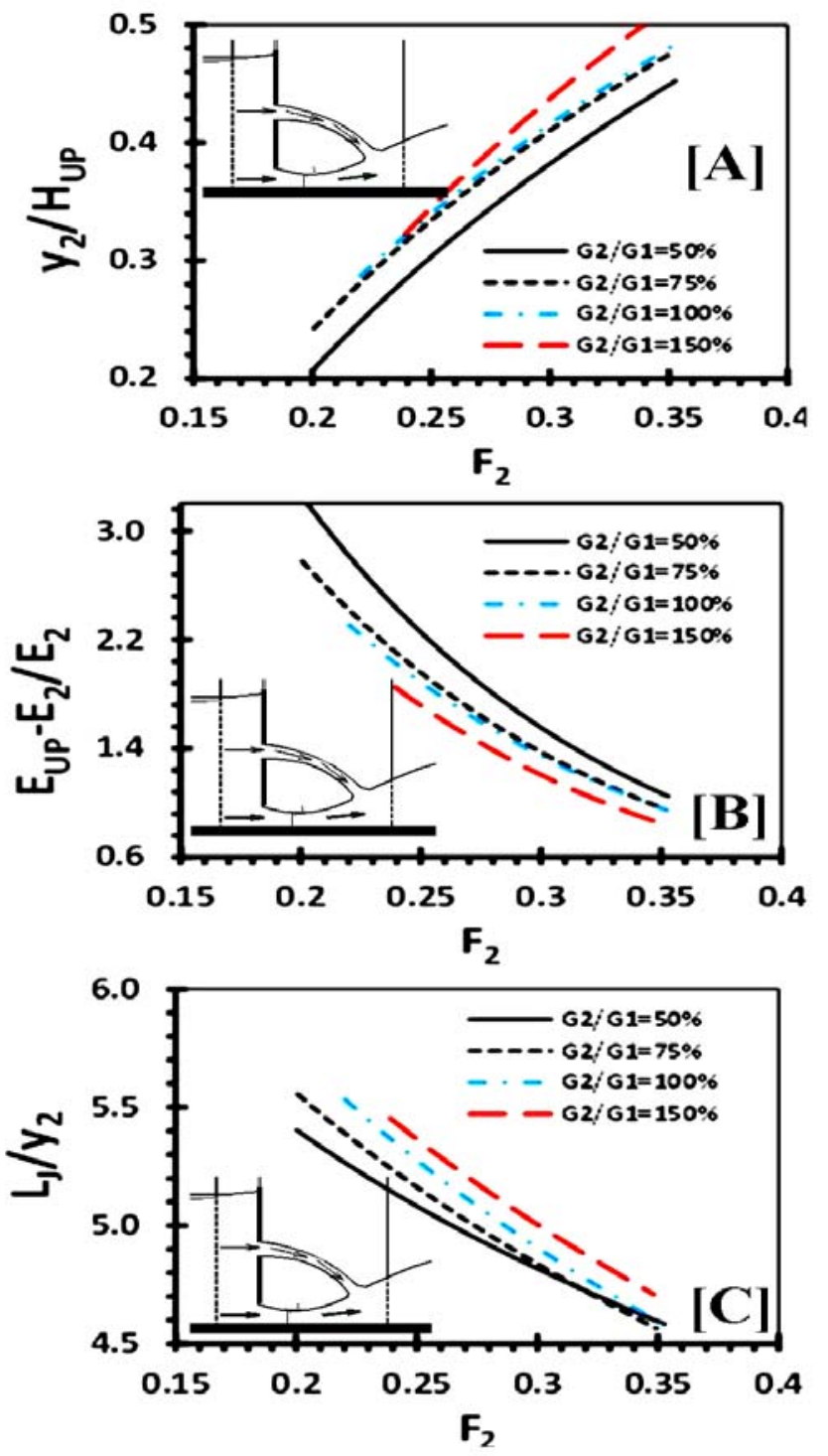

Fig. 8: The jump parameters against $F_{2}$ for $\mathrm{G}_{2} / \mathrm{G}_{1}=50 \%, \mathrm{G}_{2} / \mathrm{G}_{1}=75 \%, \mathrm{G}_{2} / \mathrm{G}_{1}=100 \%$ and $\mathrm{G}_{2} / \mathrm{G}_{1}=150 \%$ [A] $\mathrm{y}_{2} / \mathrm{H}_{\mathrm{UP}}[\mathrm{B}]\left(\mathrm{E}_{\mathrm{UP}}-\mathrm{E}_{2}\right) / \mathrm{E}_{2}$ $[\mathrm{C}] \mathrm{L}_{\mathrm{J}} / \mathrm{y}_{2}$
In addition, (TVOG) of $\mathrm{G}_{2} / \mathrm{G}_{1}=50 \%$ gives the less percentage of length of $\mathrm{H}$. jump to the end depth of jump $\mathrm{L}_{\mathrm{J}} / \mathrm{y}_{2}$, see figure (8C).

Figure (9) presents the jump parameters for the situation of (TVOG) of $\mathrm{G}_{2} / \mathrm{G}_{1}=50 \%$ and the situation of lower gate only against $F_{2}$. It can be gotten that, the situation of $\mathrm{G}_{2} / \mathrm{G}_{1}=50 \%$ decreases percentage of the end depth of jump to flow upstream gates $\mathrm{y}_{2} / \mathrm{H}_{\mathrm{UP}}$ by about $31.2 \%$ compared to the situation of the lower gate only, as existing in figure (9A).

In addition, the situation of (TVOG) of $\mathrm{G}_{2} / \mathrm{G}_{1}=50 \%$ reduces percentage of length of $\mathrm{H}$. jump to the end depth of jump $\mathrm{L}_{\mathrm{J}} / \mathrm{y}_{2}$ by about $4.3 \%$ compared to the situation of the lower gate only, as existing in figure (9C). In contrast, the situation of (TVOG) of $\mathrm{G}_{2} / \mathrm{G}_{1}=50 \%$ magnifies the percentage of lost energy via the apparatus $\left(\mathrm{E}_{\mathrm{UP}}-\mathrm{E}_{2}\right) / \mathrm{E}_{2}$ by about $52 \%$ compared to the situation of the lower gate only, as existing in figure (9B).

Through the current experimental works, there was a noticeable effect of the percentage of $\mathrm{G}_{2} / \mathrm{G}_{1}$ on the jump parameters including $\mathrm{y}_{2} / \mathrm{H}_{\mathrm{UP}}, \mathrm{L}_{\mathrm{J}} / \mathrm{y}_{2}$ and $\left(E_{U P}-E_{2}\right) / E_{2}$ for the situations of Two Vertical Overlapping Gates (TVOG). That relation is existing in figure (8). It can be gotten that, as $\mathrm{G}_{2} / \mathrm{G}_{1}$ decreases the jump parameters are improved. The reason for the improvement of jump parameters is due to the decreasing the amount of discharge passing across the upper gate to the optimum limit.

Generally, as $\mathrm{G}_{2} / \mathrm{G}_{1}$ magnifies the amount of discharge passes across the lower gate decreases and the upstream depth decreases, see figures (10A and 10B), respectively. As a direct result, the discharge through the upper gate magnifies. It plays as a pusher for the body of jump. The flow from the upper gate pushes the formed hydraulic jump. As a result, it needs a longer basin. In addition, it requires more tail flow depth to keep it in the same location in the basin, as sketched in Figure (11).

\section{The Conclusions}

This experimental paper debates the parameters of jump downstream Two Vertical Overlapping Gates (TVOG). The main concluded points are listed below:

- The experimental data for the case of the lower gate situation was compared with the Blanger Equation \& Hager (1985) and Herbrand (1973). It proves a high accuracy of the recent measures.

- Two Vertical Overlapping Gates (TVOG) of 
$\mathrm{G}_{2} / \mathrm{G}_{1}=50 \%$ gives the smaller amounts of $\mathrm{y}_{2} / \mathrm{H}_{\mathrm{UP}}, \mathrm{L}_{\mathrm{J}} / \mathrm{y}_{2}$ and the greatest $\left(\mathrm{E}_{\mathrm{UP}}-\mathrm{E}_{2}\right) / \mathrm{E}_{2}$.

- TVOG of $\mathrm{G}_{2} / \mathrm{G}_{1}=50 \%$ decreases the average amounts of $\mathrm{y}_{2} / \mathrm{H}_{\mathrm{UP}}$ and $\mathrm{L}_{\mathrm{J}} / \mathrm{y}_{2}$ by about $31.2 \%$ and $4.3 \%$ compared to the situation of the lower gate only, respectively.

- TVOG of $\mathrm{G}_{2} / \mathrm{G}_{1}=50 \%$ magnifies $\left(\mathrm{E}_{\mathrm{UP}}-\mathrm{E}_{2}\right) / \mathrm{E}_{2}$ by about $52 \%$ compared to the situation of the lower gate only,

- The amount of discharge passes across the lower gate decrease and the upstream depth decreases as $\mathrm{G}_{2} / \mathrm{G}_{1}$ increases.
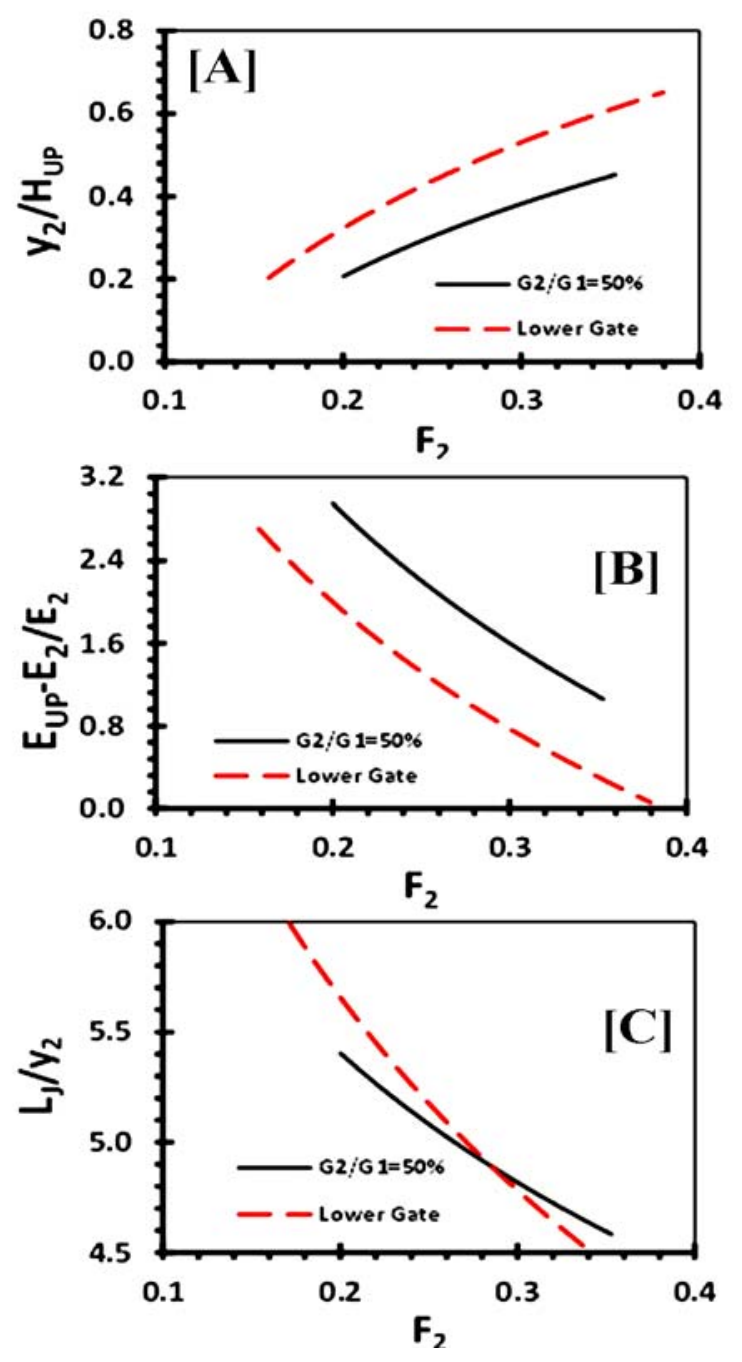

Fig. 9: The jump parameters against $F_{2}$ for $\mathrm{G}_{2} / \mathrm{G}_{1}=50 \%$, and the lower gate situation $[\mathrm{A}]$ $\mathrm{y}_{2} / \mathrm{H}_{\mathrm{UP}}[\mathrm{B}]\left(\mathrm{E}_{\mathrm{UP}}-\mathrm{E}_{2}\right) / \mathrm{E}_{2}[\mathrm{C}] \mathrm{L}_{\mathrm{J}} / \mathrm{y}_{2}$
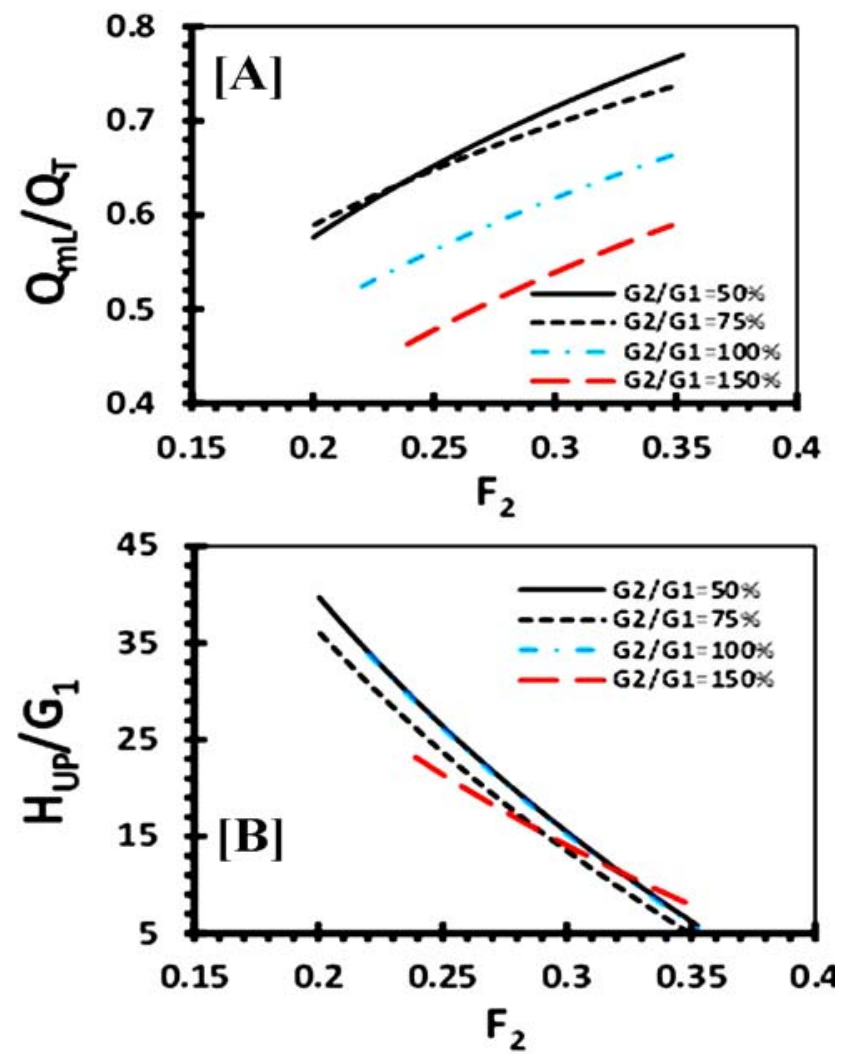

Fig. 10: [A] The percentage of $Q_{m i} / Q_{T}$ against $F_{2}$ [B] The percentage of $R_{V F} / G_{1}$ against $F_{2}$

\section{References}

[1] Abdel-Aal, G.M., Elfiky, M.M., \& Negm, A.M., (2004), "Analysis of Free Hydraulic Jump Characteristics D $\backslash \mathrm{S}$ Multi-Vent Regulators" Sc. Bull., Fac. of Eng., Ain Shams Univ., Vol. 39, No. 3, Sep. 30, Part I: Arch. and Civil Eng., PP. 475-494.

[2] Abdel-Aal, G. M., Nassar, M. A., \& Helmy, S. A., (2014a), "Improving The Hydraulic Performance of Fayouman-Type Weirs Used in The Egyptian Irrigation Canals", The Egyptian Int. J. of Engineering Sciences \& Technology, Vol. (17), No.(4).

[3] Alikhani, A., Behrozi-Rad, R., \& Fathi-Moghadam, M., (2010), "Hydraulic jump in stilling basin with vertical end sill”. Int. J. of Physical Sciences, 5(1), 25-29.

[4] Dehghani, A. A., Bashiri, H., \& Dehghani, N., (2010), "Downstream scour of combined flow over weirs and below gates", River Flow-Dittrich, Koll, Aberle \& Geisenhainer (eds) 


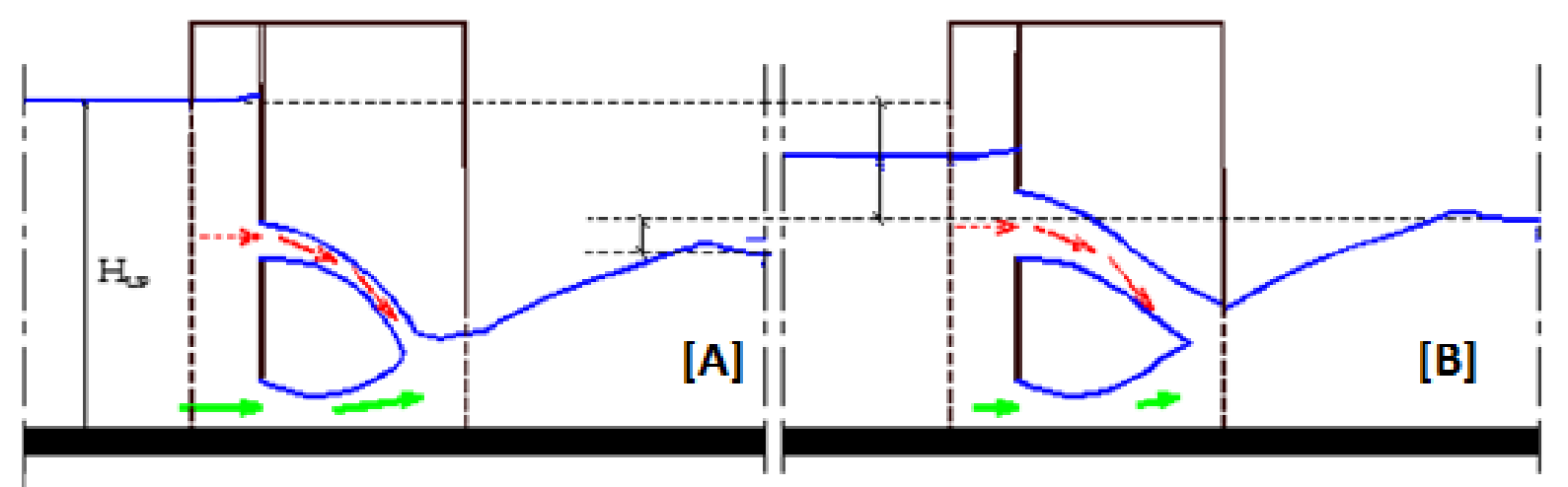

Fig. 11: Definition sketches in cases of the proposed TVOG [A] TVOG with minimum $\mathrm{G}_{2} / \mathrm{G}_{1}[\mathrm{~B}\rceil$ TVOG with most $\mathrm{G}_{2} / \mathrm{G}_{1}$

[5] Abdel-Aal, G. M., Nassar, M. A., \& Elnikhely, E. A., (2014b), "Investigating Flow Characteristics under Effect of a Modified Vertical Gate", the Egyptian Int. J. of Engineering Sciences \& Technology, Vol. (17), No.(1).

[6] Habib, A. A., \& Nassar, M. A., (2013), "Characteristics of Flow and Scour Under The Effect of Curved Steel Roughness Elements", The Egyptian Int. J. of Engineering Sciences \& Technology, Vol. (16), No.(1).

[7] Habib, A. A., \& Nassar, M. A., (2014), "Investigating Theoretically and Experimentally the Effect of A Movable Lateral Sill on Hydraulic Jump", The Egyptian Int. J. of Engineering Sciences \& Technology, Vol. (17), No. (4).

[8] Hager, W. H., (1985), "Hydraulic jump in nonprismatic rectangular channels", J. of Hydraulic Research, Vol. (23), No.(1), 21-35.

[9] Kordi, E., \& Abustan, I., (2011), "Transitional expanding hydraulic jump", Journal of Hydraulic Engineering, 138(1), 105-110.

[10] Matin, M. A., Alhamid, A. A., \& Negm, A. M., (1998), "Prediction of Sequent Depth Ratio of Hydraulic Jump in Abruptly Expanding Channel", Proc. of Int. Conference on Hydro-Science and Engineering HydroScience and Engineering ICHE98, Advances in HydroScience and Engineering (Vol. 3).
[11] Negm, A. A. M., Al-Brahim, A. M., \& Alhamid, A. A., (2002a), "Combined-free flow over weirs and below gates”, J. of Hydraulic research, Vol. (40), No. (3), 359365.

[12] Negm, A. M., Abdel-Aal, G. M., \& Habib, A. A., (2003), "Effect of location of negative step on hydraulic characteristics of jumps in radial stilling basins under free flow conditions", Proc. of Alazhar Eng. $7^{\text {th }}$ Int. Conf.

[13] Negm, A. M., Abdel-Aal, G. M., Elfiky, M.. .., Mohmed, Y. A., (2002b), "Hydraulic Characteristics Submerged Flow in Non-prismatic Stilling Basins", I: Conf. On Hydroscience and Engineering, ICHE20C Sept., Warsw, Poland, Published on CD-ROM.

[14] Negm, A. M., Abdelaal, G. M., Elfiky, M. M., Abdalla, Y. M., (2007), "Effect of Multi-Ga1 Regulators Operations on Downstream Scour Patte under Submerged Flow Conditions", Proc. IWTC11, 735-767.

[15] Saleh, O. K.., Negm, A. M., \& Ahmad, N. G., (2003), "Effect of asymmetric side sill on scour characteristics downstream of sudden expanding stilling basins", In Al-Azahr Engineering $7^{\text {th }}$ Int. Conference. Cairo Egypt. 